\title{
Antimicrobial activities of Plantactinospora sp. KBS50, a rare marine-derived actinomycete from the coastal area of Sarawak
}

\author{
Holed Juboi ${ }^{1 *}$, Siaw San Hwang ${ }^{2}$, Tiong Chia Yeo ${ }^{1}$ and Peter Morin Nissom²
}

${ }^{1}$ Sarawak Biodiversity Centre, Km. 20 Jalan Borneo Heights, Semengoh, 93250 Kuching, Sarawak, Malaysia.

${ }^{2}$ Swinburne University of Technology Sarawak Campus, Jalan Simpang Tiga, 93350 Kuching, Sarawak, Malaysia. Email: holed@sbc.org.my

Received 6 February 2018; Received in revised form 8 October 2018; Accepted 8 October 2018

\begin{abstract}
Aims: An actinomycete strain, designated KBS50, was isolated from a beach sediment sample collected from the Santubong area in Sarawak, Malaysia. This study reports on the identification, characterization and evaluation of the antimicrobial potential of this rare actinomycete.

Methodology and results: KBS50 was identified as a potentially new species of Plantactinospora genus using the $16 \mathrm{~S}$ rRNA gene sequence analysis. The rare actinomycete showed distinct morphological and physiological characteristics from other species of Plantactinospora. KBS50 exhibited strong antagonistic activities against Gram-positive bacteria (Staphylococcus aureus and Bacillus subtilis) and fungi (Aspergillus niger, Ganoderma boninense, and Rhizoctonia solani). The actinomycete also tested positive for proteolytic activity. Meanwhile, secondary screening of the cell-free culture broths and the ethyl acetate crude extracts detected antimicrobial activity against the Gram-positive bacteria only. The minimum inhibitory concentration of the crude extract against $B$. subtilis and $S$. aureus was $5.21 \pm 1.30 \mu \mathrm{g} / \mathrm{mL}$ and $15.63 \pm 0.00 \mu \mathrm{g} / \mathrm{mL}$, respectively.

Conclusion, significance and impact of study: The results presented in this paper provided an insight into the capability of Plantactinospora sp. KBS50 as a potential source of bioactive secondary metabolites compounds. This study also showed that the marine-associated environment such as the coastal area in Sarawak can be a valuable source of unique actinomycetes that can be exploited for natural product discovery.
\end{abstract}

Keywords: Marine actinomycete, proteolytic, secondary metabolites, natural product

\section{INTRODUCTION}

Rare actinomycetes, especially of marine origin, have been recognized as an alternative source of novel natural product drug candidates. Many efforts have been made to explore the marine environment for isolation of actinomycetes for secondary metabolite screening (Fiedler et al., 2005; Bredholt et al., 2008). However, isolation of marine actinomycetes from deep-sea sediment may require specialized techniques and equipment for sample collection and cultivation, thus limiting access to these valuable microorganisms. Notwithstanding that, marine-associated environment such as the mangrove and beach along the coastal area also present high diversity of actinomycetes (Amrita et al., 2012; Xu et al., 2014; Azman et al., 2015) which could serve as an alternative source for discovery of novel bioactive natural product compound.

Currently, there is a lack of data on natural product discovery from local isolates, especially actinomycetes isolated from the marine-associated environment in
Sarawak. At the same time, there is an increasing need to explore new areas for the isolation of novel source of bioactive secondary metabolite compound, owing to the decline in the discovery of new compounds as well as a surge in the incident involving antibiotic-resistant pathogens (Berdy, 2012). In the present study, an effort was made to evaluate the antimicrobial potential of a rare actinomycete, strain KBS50, which was isolated from a beach sediment sample collected from the Santubong area in Sarawak, Malaysia. This study also explores the capability of the strain in producing extracellular enzymes with cellulolytic and proteolytic activities. Production of enzymes such as protease and glucanase could be of interest as it may contribute to the antagonistic activity against fungi.

The results presented in this paper provided an insight into the capabilities of a rare actinomycete strain isolated from a marine-associated environment as a potential source of bioactive natural product compound, as well as a candidate for biocontrol agent against plant pathogenic fungi. This study also showed that the marine-associated 
environment such as the coastal area in Sarawak can be a valuable source of unique actinomycetes that can be exploited for drug discovery.

\section{MATERIALS AND METHODS}

\section{Actinomycete strain maintenance and preservation}

Strain KBS50 was maintained on the International Streptomyces Project medium 2 agar, ISP2 (Shirling and Gottlieb, 1966), while the stock cultures are stored at -80 ${ }^{\circ} \mathrm{C}$ freezer in cryovials containing $1 \mathrm{~mL}$ of $20 \%$ nutrient glycerol.

\section{Strain identification and phylogenetic analysis using 16S rRNA gene sequence}

Strain KBS50 was cultivated in $20 \mathrm{~mL}$ ISP2 broth in a 125 $\mathrm{mL}$ Erlenmeyer flask at $28^{\circ} \mathrm{C}$ for three days with constant shaking at $200 \mathrm{rpm}$. Vegetative cells were collected by centrifugation and genomic DNA (gDNA) was extracted and purified using the CTAB method adapted from Moore et al. (2004). The 16S rRNA gene sequence was amplified using the universal primers pair 27F (5'AGAGTTTGATCMTGGCTCAG-3') and 1492R (5'TACGGYTACCTTGTTACGACTT-3'). Sequencing was performed using BigDye Terminator cycle sequencing kit on an automated DNA sequencer, ABI Prism $3130 \mathrm{XL}$ Genetic Analyzer (Applied Biosystems, USA) using the same primers pair. The 16S rRNA gene was analysed for sequence similarity in the GenBank ${ }^{\circledR}$ database using the Basic Local Alignment Search Tool (BLAST $\left.{ }^{\circledR}\right)$. The phylogenetic tree was inferred using neighbour-joining method (Saitou and Nei, 1987) and evolutionary distances were computed using the Maximum Composite Likelihood method (Tamura et al., 2004) with bootstrap analysis (Felsenstein, 1985) of 1000 replicates using MEGA version 6 software package (Tamura et al., 2013). Sequence identity matrix was calculated using the BioEdit program version 7.2 (Hall, 1999).

\section{Morphological and physiological characterization}

Morphological characteristics including colony colour, mycelia and spore formation on ISP2, ISP3, ISP4 and ISP5 agar media were observed and recorded according to the method of Shirling and Gottlieb (1966). The ability of the actinomycete to grow at different concentrations of sodium chloride, $\mathrm{NaCl}(0,1,2,3,4,5,6,7,10,12,15$ and $20 \%$, w/v), different temperatures $(4,10,20,25,28,30$, 37 and $\left.40^{\circ} \mathrm{C}\right)$, and $\mathrm{pH}(4,5,6,7,8,9,10,11,12$ and 13$)$ was tested on ISP2 agar. The growth was compared relative to its growth on a standard cultivation condition (ISP2 medium, $28{ }^{\circ} \mathrm{C}, \mathrm{pH}$ 7.2). The growth was considered 'good' when it is equal or better than the growth on standard cultivation condition. Likewise, the growth was considered 'poor' when the growth is less than the growth on standard cultivation condition. The growth was observed and recorded at the 7th, 14th, 21st and 28th days of incubation. Gram staining was carried out using standard Gram stain method (Bartholomew and Finkelstein, 1958).

\section{Evaluation of extracellular enzyme production}

Carboxymethyl cellulose (CMC) agar and Avicel agar was used to evaluate the activity of endo-1,4-ß-D-glucanase and exo-1,4-ß-D-glucanase, respectively, while skim milk agar (SMA) was used to evaluate the proteolytic activity of proteases. The basal medium for CMC and Avicel agar was prepared according to Kasana et al. (2008) with the final agar containing $1 \%$ of CMC or Avicel, respectively. Meanwhile, the SMA was prepared using Nutrient Agar (NA) as the basal medium and supplemented with $2 \%$ skim milk. The actinomycete strain KBS50 was spot inoculated onto the SMA, CMC and Avicel agar test plates, and incubated at $28{ }^{\circ} \mathrm{C}$ for up to fourteen days. Glucanase activity was detected using Congo red solution as an indicator (Sazci et al., 1986; Brigitte and Aloisio, 2014). Meanwhile, the production of proteases was determined from the formation of a clear zone around the actinomycete colony on skim milk agar (Rydén et al., 1973; Alnahdi, 2012).

\section{Screening for antagonistic activity}

Antimicrobial screening was carried out to determine the antagonistic activity of strain KBS50 against representatives of Gram-negative bacteria (Escherichia coli NBRC 3301 and Pseudomonas aeruginosa NBRC 12689), Gram-positive bacteria (Staphylococcus aureus NBRC 12732 and Bacillus subtilis NBRC 3134), yeast (Saccharomyces cerevisiae ATCC 9763), and fungi (Aspergillus niger NBRC 4066, Ganoderma boninense and Rhizoctonia solani). Ganoderma boninense and $R$. solani were locally isolated plant pathogenic fungi strains maintained at the Swinburne University of Technology Sarawak Campus. The antagonistic activity was evaluated using 4 types of media, namely ISP2, MB (per Liter: Soluble starch, $5.0 \mathrm{~g}$, glucose, $5.0 \mathrm{~g}$, meat extract, $1.0 \mathrm{~g}$, yeast extract, $1.0 \mathrm{~g}, \mathrm{~N}-\mathrm{Z}-\mathrm{Case}, 2.0 \mathrm{~g}, \mathrm{NaCl}, 2.0 \mathrm{~g}$, $\mathrm{CaCl}_{2} \cdot 2 \mathrm{H}_{2} \mathrm{O}, 2.0 \mathrm{~g}$, agar, $15.0 \mathrm{~g}, \mathrm{pH} 7.2 \pm 0.2$ ), FM1 (per Liter: Corn starch, $20.0 \mathrm{~g}$, Glucose, $10.0 \mathrm{~g}, \mathrm{~N}-\mathrm{Z}$-Amine type A, $5.0 \mathrm{~g}$, Yeast extract, $5.0 \mathrm{~g}, \mathrm{CaCO}_{3}, 1.0 \mathrm{~g}$, agar, $15.0 \mathrm{~g}, \mathrm{pH} 7.2 \pm 0.2$ ), and FM8 (per Liter: Sago starch, $5.0 \mathrm{~g}$, peptone N-Z-Soy, $4.0 \mathrm{~g}$, wheat flour, $5.0 \mathrm{~g}$, glucose, $3.0 \mathrm{~g}$, yeast extract, $3.0 \mathrm{~g}, \mathrm{MgSO}_{4} \cdot 7 \mathrm{H}_{2} \mathrm{O}, 0.5 \mathrm{~g}, \mathrm{KH}_{2} \mathrm{PO}_{4}$, $0.25 \mathrm{~g}, \mathrm{~K}_{2} \mathrm{HPO}_{4}, 0.25 \mathrm{~g}$, Agar, 15.0, pH $7.2 \pm 0.2$ ), using modified perpendicular streak method (Velho-Pereira and Kamat, 2011; Gebreyohannes et al., 2013).

Standardized inoculums of bacteria and yeast were prepared according to Andrews (2001) from overnight cultures of the test strains in Luria Broth (LB) and Sabouraud Dextrose Broth (SDB), for bacteria and yeast at $37^{\circ} \mathrm{C}$ and $30^{\circ} \mathrm{C}$, respectively. A sterile cotton swab was used to streak the test strains as a straight line perpendicular to the seven-day old actinomycete culture. Test plates were incubated at $37^{\circ} \mathrm{C}$ for $24 \mathrm{~h}$ and $30^{\circ} \mathrm{C}$ for $48 \mathrm{~h}$ for bacteria and yeast, respectively. The growth inhibition of test strains along the streak line (measured in 
$\mathrm{mm}$ ) was used as an indication of the test strains' susceptibility towards the bioactive metabolites produced by KBS50 on the agar media. The test was carried out in triplicates.

For antagonistic activity against fungi, mycelia plugs of seven-day old fungi test strains grown on Potato Dextrose Agar (PDA) at $28^{\circ} \mathrm{C}$ were prepared using sterile straw (6 $\mathrm{mm}$ in diameter) and inoculated onto the perpendicular streak agar plates at $25 \mathrm{~mm}$ distance from the seven-day old actinomycete culture. Control plates without actinomycete culture were inoculated similarly. Inhibition of fungi mycelia growth on the test plates was recorded after seven days of incubation at $28{ }^{\circ} \mathrm{C}$. The measurement was taken on radial growth of fungal mycelium in the direction towards actinomycete culture. Percentage inhibition of radial growth (PIRG) over control was calculated as follow:

Where;

$$
P I R G=[C-T] / C \times 100
$$

C - Radial growth of fungi test strain on control plate (in $\mathrm{mm})$.

$\mathrm{T}$ - Radial growth of fungi test strain on test plate (in $\mathrm{mm}$ ). One-way ANOVA was used to compare the level of significance in the inhibition of test strain on different agar media, using SPSS version 15 (SPSS Inc.).

\section{Secondary screening for antimicrobial activity}

Strain KBS50 was cultivated in $50 \mathrm{~mL}$ fermentation broths (SP2, MB, FM1 and FM8), in $125 \mathrm{~mL}$ Erlenmeyer flask. Fermentation was carried out at $28^{\circ} \mathrm{C}$ for seven days with constant shaking at $200 \mathrm{rpm}$. Cell-free culture broths (CFBs) were collected by centrifugation at $4,000 \mathrm{rpm}$ for 10 minutes, and filter-sterilized using $0.2 \mu \mathrm{m}$ filters. Secondary metabolites were extracted from the spent broths using an equal volume of ethyl acetate, twice, then dried in vacuo using SpeedVac ${ }^{\mathrm{TM}}$ Concentrator (Thermo Scientific). The CFBs and crude extracts were tested for antimicrobial activity against $E$. coli NBRC 3301, $P$. aeruginosa NBRC 12689, S. aureus NBRC 12732, $B$. subtilis NBRC $3134, S$. cerevisiae ATCC 9763, and $A$. niger NBRC 4066 using agar-well diffusion assay (AwDA).

Sterilized Muller-Hinton and Sabouraud Dextrose liquid agar were inoculated with the test strains for a final concentration of $10^{6}$ cells $/ \mathrm{mL}$ and $10^{5}$ cells $/ \mathrm{mL}$ for bacteria and yeast/fungi, respectively. Ten $\mathrm{mL}$ of the inoculated liquid agar were transferred into $90 \mathrm{~mm}$ diameter Petri dishes to solidify. The agar wells were prepared using sterilized straw of $6 \mathrm{~mm}$ in diameter. The dried crude extracts were reconstituted in $100 \%$ dimethyl sulfoxide (DMSO) to prepare crude extract stock solution of $100 \mu \mathrm{g} / \mathrm{mL}$ concentration, then further diluted to 2.5 $\mathrm{mg} / \mathrm{mL}$ using sterile reverse osmosis water. Forty $\mu \mathrm{L}$ of the CFBs and crude extracts solution was loaded into the agar wells for antimicrobial testing. The antibiotics chloramphenicol (100 ppm for Gram-positive bacteria, and $400 \mathrm{ppm}$ for Gram-negative bacteria) and nystatin (100 ppm for yeast/fungi) were used as positive controls, while the CFBs and the crude extracts of non-inoculated media, and $2.5 \%$ DMSO solution were used as the negative control. The concentrations of antibiotics used for the controls were slightly higher than the suggested ranges (Andrews, 2001). The experiment was carried out in triplicate. The assay plates for bacteria were incubated at $37^{\circ} \mathrm{C}$ for $24 \mathrm{~h}$, while the assay plates for yeast/fungi were incubated at $30{ }^{\circ} \mathrm{C}$ for $48 \mathrm{~h}$. The diameter of inhibition zone was measured (in $\mathrm{mm}$ ) to determine the antimicrobial activity. The antimicrobial data were analyzed using one-way ANOVA using SPSS version 15 (SPSS Inc.) to determine the significance level of inhibition among the CFBs and the crude extracts.

\section{Minimum inhibitory concentration of crude extracts}

The minimum inhibitory concentration (MIC) of the ISP2 crude extract against $B$. subtilis and $S$. aureus was determined using broth microdilution method adapted from Andrews (2001). The wells in 96 well plates were seeded with $75 \mu \mathrm{L}$ of standardized test strain of $2 \times 10^{6}$ cells $/ \mathrm{mL}$. Crude extract solution of $100 \mathrm{mg} / \mathrm{mL}$ prepared in $100 \%$ DMSO was diluted to $2 \mathrm{mg} / \mathrm{mL}$ with subsequent two-fold dilutions for 10 different concentrations using Mueller-Hinton broth. From each dilution point, $75 \mu \mathrm{L}$ was added to the inoculated wells. Chloramphenicol as a positive control was prepared similarly. Wells containing $150 \mu \mathrm{L}$ test strain without the addition of extract or antibiotic was prepared as the growth control. The experiment was carried out in triplicate. Initial optical density (OD) was measured using $600 \mathrm{~nm}$ wavelength. The plates were then incubated at $37^{\circ} \mathrm{C}$ for $24 \mathrm{~h}$ before the final OD reading was measured at $600 \mathrm{~nm}$. The MIC was measured as the least concentration of crude extract or antibiotic in which no visible growth was detected.

\section{RESULTS AND DISCUSSION}

\section{Actinomycete strain identification and phylogenetic analysis}

The identity of KBS50 was established using a nearcomplete 16S rRNA gene sequence of 1326 bp long, which was within the recommended length for species description (Stackebrandt et al., 2002). BLAST analysis showed that KBS50 had the highest sequence similarity with Plantactinospora species, where four species, namely $P$. mayteni, $P$. siamensis, $P$. endophytica, and $P$. veratri, produced the top four significant alignments of $98 \%$ identity with KBS50's 16S rRNA gene sequence. Other sequences producing significant alignments results were comprised of other members of Micromonosporaceae such as Verrucosispora, Polymorphospora, Micromonospora and Salinispora with sequence identity between $96-97 \%$.

Phylogenetic tree constructed using the 16S rRNA genes showed that KBS50 formed a distinct monophyletic clade together with other members of Plantactinospora. The node showing the relatedness of KBS50 with members of Plantactinospora species was supported by a bootstrap value of $72 \%$ in the neighbour-joining tree 
Malays. J. Microbiol. Vol 15(2) 2019, pp. 111-119

DOI: http://dx.doi.org/10.21161/mjm.180050

(Figure 1). Sequence identity matrix showed the highest identity with $P$. mayteni $(97.9 \%)$, followed by $P$. siamensis (97.7\%), P. endophytica (97.5\%), P. veratri $(97.5 \%), P$. sonchi $(97.2 \%)$, and $P$. soyae $(96.9 \%)$. Based on the cutoff point of $98.7 \%$ gene sequence similarity recommended by Stackebrandt and Ebers (2006),

actinomycete strain KBS50 can be considered as a new species of Plantactinospora. The 16S rRNA gene sequence of KBS50 was deposited into GenBank ${ }^{\circledR}$ nucleotide database under the accession number KY348801.

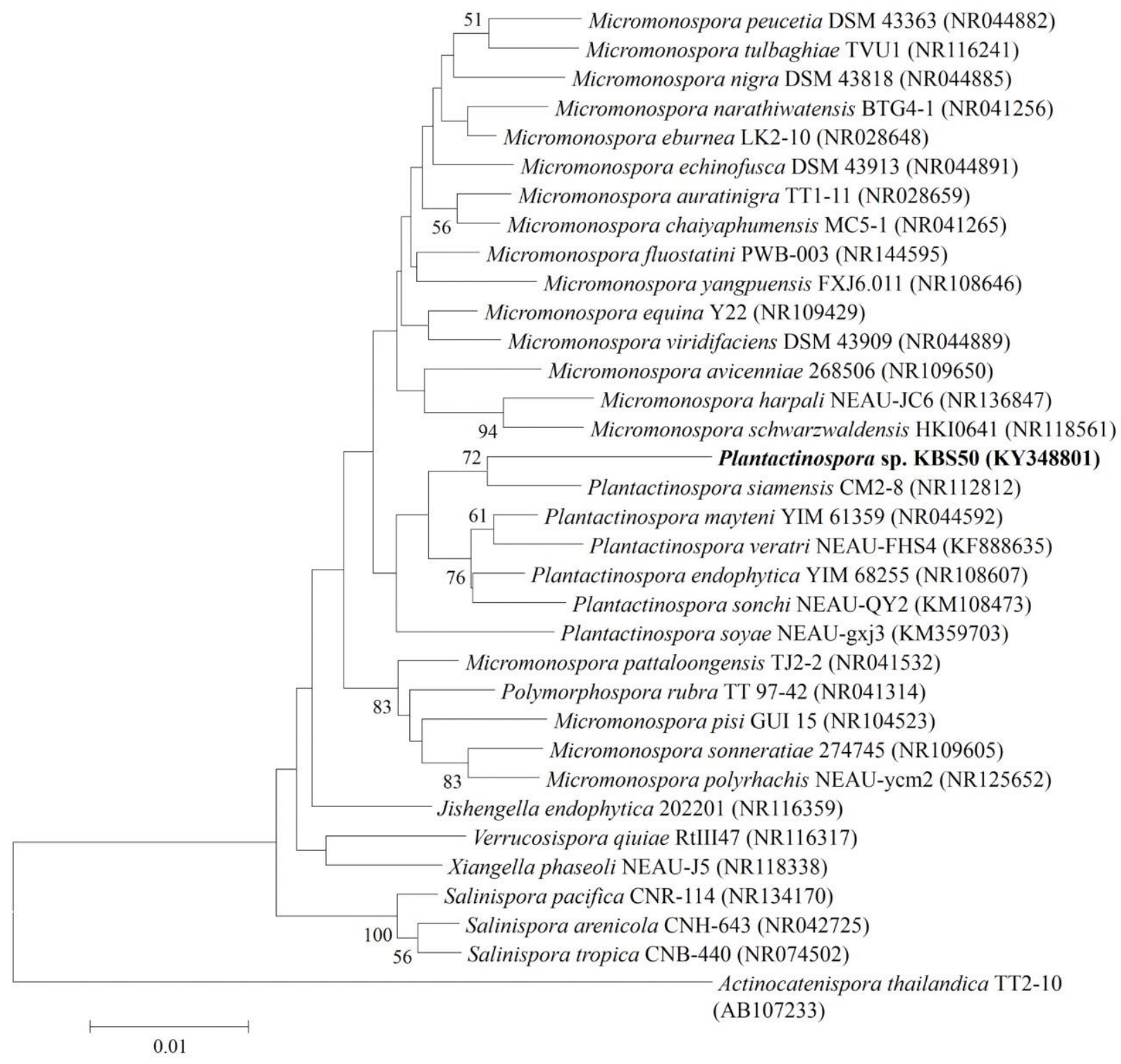

Figure 1: The neighbour-joining tree showing the relationship between strain KBS50 and other species of the genus Plantactinospora. Bootstrap values $(\geq 50 \%)$ based on 1000 replications are indicated at the branch point. Actinocatenispora thailandica TT2-10 sequence (accession no. AB107233) served as the outgroup. Bar = 0.01 nucleotide substitutions per site. 


\section{Morphological and physiological characteristics of KBS50}

Strain KBS50 is a Gram-positive actinomycete that forms extensively branched substrate mycelia on which the spores of approximately 0.2-0.4 $\mu \mathrm{m}$ in diameter appeared to be borne singly (Figure 2). The strain formed circular, slightly convex colonies with no formation of aerial mycelia detected on all agar medium tested. Good growth was observed on ISP2, ISP3 and ISP4, while poor growth was observed on ISP5 medium. The colonies colour was orange-yellow on ISP2, ISP3 and ISP4 to slightly pale orange-yellow on ISP5 medium (Figure 3 ). No soluble pigments were observed on any of the media tested.

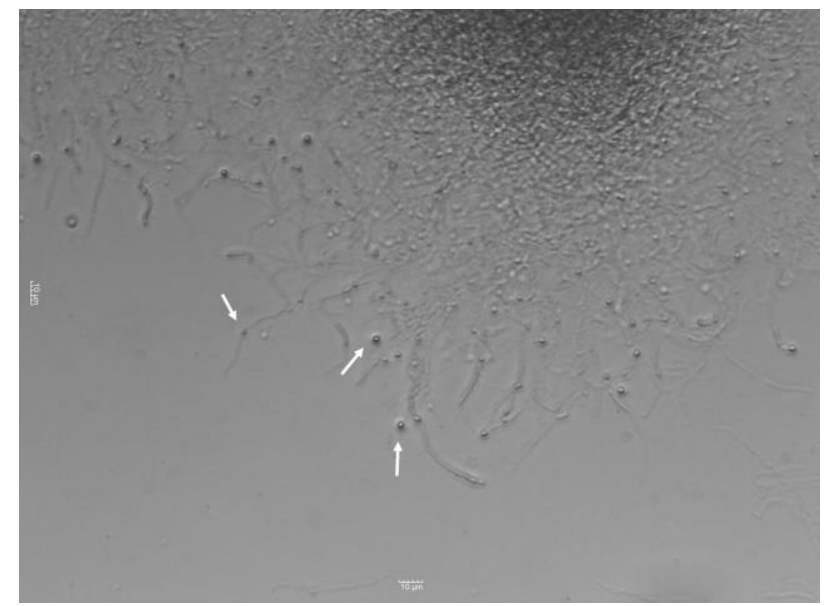

Figure 2: Substrate mycelia of strain KBS50 growing on ISP2 agar. Arrows indicate the spores structure formed on the substrate mycelia. The picture was taken from a fourteenth-day old culture using light microscope under $50 \times$ objective lens. Scale bar $=10 \mu \mathrm{m}$.

The strain grew well on ISP2 agar with up to $6 \% \mathrm{NaCl}$ concentration. On ISP2 agar with $7 \% \mathrm{NaCl}$, the colonies grew poorly but growth was evident from the presence of poorly developed substrate mycelia as observed under a light microscope after twenty-one day of incubation. No growth was observed at $10 \%$ and a higher concentration of $\mathrm{NaCl}$ tested. Its ability to tolerate up to $7 \% \mathrm{NaCl}$ concentration was higher than other species of Plantactinospora, which can only tolerate between 1-3\% $\mathrm{NaCl}$ (Qin et al., 2009; Thawai et al., 2010; Zhu et al., 2012; Ma et al., 2015; Xing et al., 2015). Interestingly, the genus Plantactinospora is only distantly related to Salinispora, a genus of true marine actinomycetes isolated from deep-sea sediment (Maldonado et al., 2005). KBS50 shared $96.9-97.0 \%$ of $16 \mathrm{~S}$ rRNA gene sequence similarity with Salinispora species. Tolerance to the high concentration of $\mathrm{NaCl}$ may have enabled strain KBS50 to survive the high salinity environment, although it does not require $\mathrm{NaCl}$ or seawater for growth, unlike its true marine relatives. KBS50 was able to grow at the incubation temperature of $20-37^{\circ} \mathrm{C}$, with very good growth observed between $25-30{ }^{\circ} \mathrm{C}$. Poor growth was observed at $20^{\circ} \mathrm{C}$ while no growth was observed at $4{ }^{\circ} \mathrm{C}$, $10{ }^{\circ} \mathrm{C}$ and $40{ }^{\circ} \mathrm{C}$. Meanwhile, the strain showed good growth on ISP2 agar with $\mathrm{pH} \mathrm{6-11.} \mathrm{The} \mathrm{minimum} \mathrm{and}$ maximum $\mathrm{pH}$ tolerated, on which the strain grew poorly, were $\mathrm{pH} 5$ and $\mathrm{pH} \mathrm{12,} \mathrm{respectively.} \mathrm{No} \mathrm{growth} \mathrm{was}$ observed on ISP2 agar with $\mathrm{pH} 4$ and $\mathrm{pH} 13$.

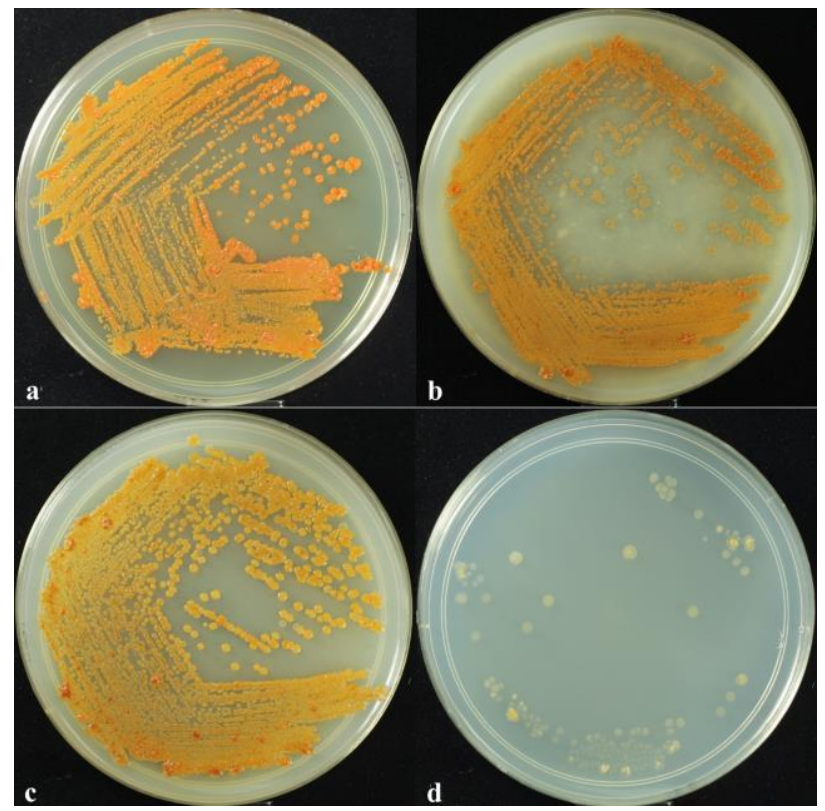

Figure 3: Colony morphology of Plantactinospora sp. KBS50 on ISP2 (a), ISP3 (b), ISP4 (c), and ISP5 (d) agar medium. The pictures were taken on the fourteenth day of incubation at $28^{\circ} \mathrm{C}$.

Physiological characteristics of strain KBS50 that clearly distinguish it from other Plantactinospora species include its ability to tolerate a higher concentration of $\mathrm{NaCl}$, higher $\mathrm{pH}$, and its inability to grow at an incubation temperature of $40^{\circ} \mathrm{C}$. These physiological differentiations might have resulted from the strain adaptation to its new environment (Retchless and Lawrence, 2012). Meanwhile, the basic morphological characteristics of strain KBS50 on agar media, such as the formation of substrate mycelium, type of sporulation, and colony colour, were somewhat similar to Plantactinospora species and also shared with many members of Micromonosporaceae.

\section{Extracellular enzyme activity}

Actinomycete strain KBS50 was tested positive for proteolytic activity as demonstrated by the formation of the clear zone on SMA agar (Figure 4). The diameter of the clear zone was recorded at $23.67 \pm 0.88 \mathrm{~mm}$ on the seventh day and increased to $44.00 \pm 1.00 \mathrm{~mm}$ on the fourteenth day, demonstrates strong production of proteases which were excreted to the extracellular 
environment. On the other hand, no glucanase activity was detected on CMC or Avicel agar.

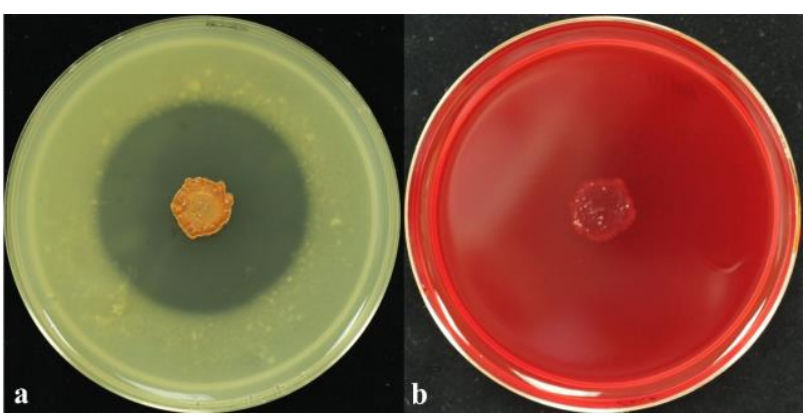

Figure 4: Extracellular enzyme activity of KBS50. The strain was positive for proteolytic activity based on the formation of clear area around the actinomycete colony on SMA agar (a). No glucanase activity was detected on CMC agar stained with $1 \%$ Congo red (b). The pictures were taken on the fourteenth day of incubation at $28{ }^{\circ} \mathrm{C}$.

\section{Antagonistic activity of Plantactinospora sp. KBS50}

The Plantactinospora genus is a relatively new group of rare actinomycetes within the Micromonosporaceae family, and their antimicrobial activity is not well reported. Most of the species in this genus were isolated from plant tissues such as roots and leaves, indicating their ecological association with the plants. The fact that many endophytic actinomycetes are often associated with having antimicrobial activity (Strobel and Daisy, 2003; Taechowisan et al., 2003; Golinska et al., 2015) is a potential aspect that can be explored on these endophytic Plantactinospora species. Meanwhile, the origin of KBS50 as a marine-associated actinomycete is an interesting factor in the screening of its antimicrobial activities. Over the years, several notable discoveries of novel natural product compounds were made from marine actinomycetes especially from the Salinispora species (Udwary et al., 2007; Matsuda et al., 2009). Strain KBS50's close association with these marine actinomycetes may indicate its potential as a producer of bioactive secondary metabolite compounds.

Table 1: Antagonistic activity of strain KBS50 against $B$. subtilis and $S$. aureus on the perpendicular streak assay.

\begin{tabular}{lll}
\hline Media & $\begin{array}{l}\text { Inhibition of bacteria test } \\
\text { Standard error of the mean }\end{array}$ & \\
\cline { 2 - 3 } & B. subtilis & S. aureus \\
\hline ISP2 & $15.67 \pm 0.67$ & $17.00 \pm 0.00$ \\
MB & $23.67 \pm 0.88$ & $21.33 \pm 0.33$ \\
FM1 & $18.67 \pm 0.67$ & $15.00 \pm 0.58$ \\
FM8 & $2.00 \pm 0.00$ & $3.67 \pm 0.33$ \\
\hline
\end{tabular}

KBS50 demonstrated strong antagonistic activity against representatives of the Gram-positive bacteria, $B$. subtilis and $S$. aureus. The antagonistic activity was observed on all four types of agar media tested (Table 1), although there was a significant difference in the growth inhibition as determined by one-way ANOVA: $S$. aureus $(F(3,8)=206.400, p=0.000)$, B. subtilis $(F(3,8)=$ $408.733, p=0.000)$. The inhibition of both test strains was significantly stronger on MB agar compared to ISP2, FM1 and FM8 $(p<0.05)$. Meanwhile, KBS50 also exhibited antagonistic activity against fungi test strains $(A$. niger, $G$. boninense and $R$. solani) on the perpendicular streak assay (Table 2). There was a significant difference in inhibition on the four type of agar as determined by oneway ANOVA: $A$. niger $(F(3,8)=1663.631, p=0.000), G$. boninense $(F(3,8)=19.298, p=0.001)$, R. solani $(F(3,8)$ $=83.264, p=0.000)$. Significantly strong inhibition of $A$. niger was recorded on $\mathrm{MB}$ agar $(72.59 \pm 0.74 \%)$ as compared to FM1 (46.67 $\pm 1.28 \%, p=0.000)$ and FM8 $(46.67 \pm 0.00 \%, p=0.000)$. Significantly strong inhibition of $G$. boninense was also recorded on MB agar (53.33 \pm $1.92 \%, p<0.05)$. The inhibitory effect of KBS50 on the radial growth of fungal mycelium toward the actinomycete culture on MB agar plates is shown in Figure 5.

Table 2: Antagonistic activity of strain KBS50 against fungi test strains on the perpendicular streak assay.

\begin{tabular}{llll}
\hline Media & \multicolumn{3}{l}{$\begin{array}{l}\text { Percentage inhibition of radial growth (PIRG) } \pm \\
\text { Standard error of the mean }\end{array}$} \\
\cline { 2 - 4 } & A. niger & G. boninense & R. solani \\
\hline ISP2 & - & $37.75 \pm 0.25$ & - \\
MB & $72.59 \pm 0.74$ & $53.33 \pm 1.92$ & $42.22 \pm 4.63$ \\
FM1 & $46.67 \pm 1.28$ & $38.87 \pm 2.04$ & - \\
FM8 & $46.67 \pm 0.00$ & $36.92 \pm 2.15$ & - \\
\hline
\end{tabular}

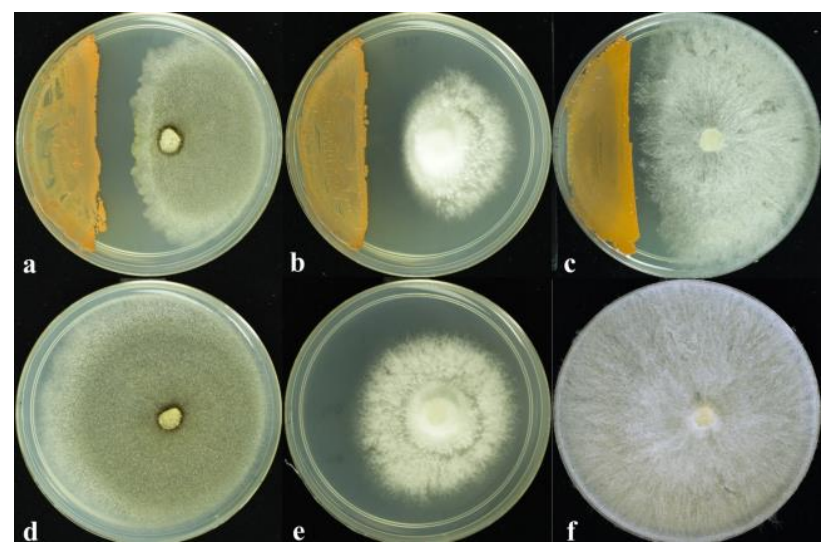

Figure 5: Inhibition of radial growth of $A$. niger (a), G. boninense (b) and $R$. solani (c) on MB agar medium as compared to their growth on the control plates $(d, e$, and $f$, respectively). The picture was taken on the seventh-day of incubation at $28^{\circ} \mathrm{C}$. 


\section{Secondary screening and determination of MIC}

The CFBs of strain KBS50 exhibited antimicrobial activity against the Gram-positive bacteria only. There was a significant difference in the antimicrobial activity among the CFB as determined by one-way ANOVA: $B$. subtilis $(F(3,8)=332.000, p=0.000)$, S. aureus $(F(3,8)=$ $507.167, p=0.000)$. The CFB of ISP2 recorded the strongest antimicrobial activity against $B$. subtilis (16.33 \pm $0.33 \mathrm{~mm}, p<0.05)$. Meanwhile, the CFB of ISP2 and FM8 showed no significant difference in the inhibition of $S$. aureus $(p=0.067)$. No antimicrobial activity was recorded from the CFB of MB medium.

The crude extracts of actinomycete strain KBS50 exhibited similar antimicrobial activity as the CFBs, which only inhibited the growth of Gram-positive bacteria (Table 3). There was a significant difference in the antimicrobial activity among the crude extracts as determined by oneway ANOVA: $B$. subtilis $(F(3,8)=41.867, p=0.000), S$. aureus $(F(3,8)=984.000, p=0.000)$. The crude extract from ISP2 broth recorded the strongest antimicrobial activity against $B$. subtilis $(17.67 \pm 0.33 \mathrm{~mm}, p<0.05)$ and $S$. aureus $(12.33 \pm 0.33 \mathrm{~mm}, p<0.05)$. The MIC of ISP2 crude extract was determined at $5.21 \pm 1.30 \mu \mathrm{g} / \mathrm{mL}$ against $B$. subtilis and $15.63 \pm 0.00 \mu \mathrm{g} / \mathrm{mL}$ against $S$. aureus. As a comparison, the MIC of chloramphenicol as determined from this experiment was $3.91 \pm 0.00 \mu \mathrm{g} / \mathrm{mL}$ for $B$. subtilis and $5.21 \pm 1.30 \mu \mathrm{g} / \mathrm{mL}$ for $S$. aureus.

Table 3: Antimicrobial activity of crude extracts against $B$. subtilis and $S$. aureus in AwDA.

\begin{tabular}{lll}
\hline Crude extract & $\begin{array}{l}\text { Inhibition diameter } \\
\text { error of the mean }\end{array}$ & \pm Standard \\
\cline { 2 - 3 } & B. subtilis & S. aureus \\
\hline ISP2 & $17.67 \pm 0.33$ & $12.33 \pm 0.33$ \\
MB & $12.00 \pm 0.00$ & $9.00 \pm 0.00$ \\
FM1 & $15.67 \pm 0.67$ & $8.00 \pm 0.00$ \\
FM8 & $14.00 \pm 0.00$ & - \\
Positive control & $17.67 \pm 0.33$ & $16.00 \pm 0.58$ \\
(CP100) & & \\
\hline
\end{tabular}

It has been reported that media composition can affect the production of secondary metabolite compounds from actinomycetes (Bode et al., 2002; Bills et al., 2008; Wang et al., 2013; Hewage et al., 2014). Therefore, four different types of media were employed in the antimicrobial screening to increase the chances of discovering antimicrobial activity against the test microorganism. The antimicrobial screening showed that the activity was indeed affected by the cultivation media, although the differences were limited to the growth inhibition level against the test strains and did not increase the antimicrobial spectrum. While strong antagonistic activity against $S$. aureus, $B$. subtilis, $A$. niger, $G$. boninense and $R$. solani was observed and recorded on the perpendicular streak assay, the secondary screening of CFBs and crude extracts using the AwDA only detected antimicrobial activity against the Gram-positive bacteria. It was possible that the antagonistic activities against these fungi strains were the result of the proteolytic activity of proteases on the agar media. Proteases activity could be linked to antagonistic activity against fungi test strains by inhibiting the growth of fungal mycelia (Illakkiam et al., 2013; Liu and Yang, 2013). Screening of CFBs from liquid cultures, however, did not result in the inhibition of $A$. niger, suggesting that the antifungal compound was produced selectively on solid agar medium but not in the fermentation broth. Other possible reason could be the presence of a very low amount of the antifungal compound in the crude extracts that was below its effective inhibitory concentration.

\section{CONCLUSION}

Based on the results presented in this study, the marinederived rare actinomycete Plantactinospora sp. KBS50 was found to be an interesting producer of secondary metabolites especially compounds with antimicrobial activity against the Gram-positive bacteria. The antimicrobial screening of the crude extracts indicates the potential influence of nutrient composition on the production of bioactive secondary metabolites by the actinomycete strain. Although this study did not involve the screening of other species of Plantactinospora, our findings may reflect the potential capabilities of the member of this genus to produce bioactive secondary metabolite compounds, given their unique taxonomical position and the endophytic nature of most of the species. Future study may focus on the effect of medium compositions and cultivation parameters towards the production of secondary metabolites by KBS50, as well as the isolation and identification of the bioactive compounds. It is also within our interest to sequence and analyses the complete genome of this unique actinomycete to further unravel its natural product biosynthetic capability.

\section{ACKNOWLEDGEMENTS}

We thank Mohd Fadeli, Noor Mehrunnika and Sunita Sara Gill Shamsul for their assistance in the isolation and cultivation of actinomycetes from beach sediment samples collected from the Santubong area in Sarawak. We also thank Arzie Ramli for her assistance with the DNA sequencing. This research was supported by the research grant from the Chief Minister Department of the Sarawak State Government, Malaysia.

\section{REFERENCES}

Alnahdi, H. S. (2012). Isolation and screening of extracellular proteases produced by new isolated Bacillus sp. Journal of Applied Pharmaceutical Science 2(9), 71-74.

Amrita, K., Nitin, J. and Devi, C. S. (2012). Novel bioactive compounds from mangrove derived 
actinomycetes. International Research Journal of Pharmacy 3(9), 25-29.

Andrews, J. M. (2001). Determination of minimum inhibitory concentrations. Journal of Antimicrobial Chemotherapy 48, 5-16.

Azman, A. S., Othman, I., Velu, S. S., Chan, K. G. and Lee, L. H. (2015). Mangrove rare actinobacteria: Taxonomy, natural compound, and discovery of bioactivity. Frontiers in Microbiology 6, 1-15.

Bartholomew, J. W. and Finkelstein, H. (1958). Relationship of cell wall staining to Gram differentiation. Journal of Bacteriology 75(1), 77-84.

Berdy, J. (2012). Thoughts and facts about antibiotics: Where we are now and where we are heading. Journal of Antibiotics 65(8), 385-395.

Bills, G. F., Platas. G., Fillola, A., Jiménez, M. R., Collado, J., Vicente, F., Martín, J., González, A., Bur-Zimmermann, J., Tormo, J. R. and Peláez, F. (2008). Enhancement of antibiotic and secondary metabolite detection from filamentous fungi by growth on nutritional arrays. Journal of Applied Microbiology 104(6), 1644-1658.

Bode, H. B., Bethe, B., Höfs, R. and Zeeck, A. (2002). Big effects from small changes: Possible ways to explore nature's chemical diversity. ChemBioChem 3(7), 619-627.

Bredholt, H., Fjaervik, E., Johnsen, G. and Zotchev, S. B. (2008). Actinomycetes from sediments in the Trondheim Fjord, Norway: Diversity and biological activity. Marine Drugs 6(1), 12-24.

Brigitte. S. O. C. and Aloisio, F. C. J. (2014). Screening and detection of extracellular cellulases (endo- and exo-glucanases) secreted by filamentous fungi isolated from soils using rapid tests with chromogenic dyes. African Journal of Biotechnology 13(52), 46944701.

Felsenstein, J. (1985). Confidence limits on phylogenies: An approach using the bootstrap. Evolution 39(4), 783-791.

Fiedler, H. P., Bruntner, C., Bull, A. T., Ward, A. C., Goodfellow, M., Potterat, O., Puder, C. and Mihm, G. (2005). Marine actinomycetes as a source of novel secondary metabolites. Antonie van Leeuwenhoek 87(1), 37-42.

Gebreyohannes, G., Moges, F., Sahile, S. and Raja, N. (2013). Isolation and characterization of potential antibiotic producing actinomycetes from water and sediments of Lake Tana, Ethiopia. Asian Pacific Journal of Tropical Biomedicine 3(6), 426-435.

Golinska, P., Wypij, M., Agarkar, G., Rathod, D., Dahm, H. and Rai, M. (2015). Endophytic actinobacteria of medicinal plants: Diversity and bioactivity. Antonie van Leeuwenhoek 108(2), 267-289.

Hall, T. A. (1999). BioEdit: A user-friendly biological sequence alignment editor and analysis program for Windows 95/98/NT. Nucleic Acids Symposium Series (41), 95-98.

Hewage, R. T., Aree, T., Mahidol, C., Ruchirawat, S. and Kittakoop, P. (2014). One strain-many compounds (OSMAC) method for production of polyketides, azaphilones, and an isochromanone using the endophytic fungus Dothideomycete $\mathrm{sp}$. Phytochemistry 108, 87-94.

Illakkiam, D., Anuj, N. L., Ponraj, P., Shankar, M., Rajendhran, J. and Gunasekaran, P. (2013). Proteolytic enzyme mediated antagonistic potential of Pseudomonas aeruginosa against Macrophomina phaseolina. Indian Journal of Experimental Biology 51(11), 1024-1031.

Kasana, R. C., Salwan, R., Dhar, H., Dutt, S. and Gulati, A. (2008). A rapid and easy method for the detection of microbial cellulases on agar plates using Gram's iodine. Current Microbiology 57(5), 503-507.

Liu, Y. and Yang, Q. (2013). Cloning and heterologous expression of serine protease SL41 related to biocontrol in Trichoderma harzianum. Journal of Molecular Microbiology and Biotechnology 23(6), 431439.

Ma, Z., Fan, J., Zhao, S., Liu, C., Li, C., Li, J., Wang, X., He, H. and Xiang, W. (2015). Plantactinospora sonchi sp. nov., an actinobacterium isolated from the leaves of common sowthistle (Sonchus oleraceus L.). International Journal of Systematic and Evolutionary Microbiology 65(12), 4895-4901.

Maldonado, L. A., Fenical, W., Jensen, P. R., Kauffman, C. A., Mincer, T. J., Ward, A. C., Bull, A. T. and Goodfellow, M. (2005). Salinispora arenicola gen. nov., sp. nov. and Salinispora tropica sp. nov., obligate marine actinomycetes belonging to the family Micromonosporaceae. International Journal of Systematic and Evolutionary Microbiology 55(5), 1759-1766.

Matsuda, S., Adachi, K., Matsuo, Y., Nukina, M. and Shizuri, Y. (2009). Salinisporamycin, a novel metabolite from Salinispora arenicola. Journal of Antibiotics 62(9), 519-526.

Moore, E., Arnscheidt, A., KrÜger, A., StrÖmpl, C. and Mau, M. (2004). Simplified protocols for the preparation of genomic DNA from bacterial cultures. In: Molecular Microbiology Ecology Manual. Kowalchuk, G. A., Bruijn, F. J., Head, I. M., Akkermans, A. D. and Elsas, J. D. (eds.). Kluwer Academic Publishers, Dodrecht, The Netherlands. pp. 3-18.

Qin, S., Li, J., Zhang, Y. Q., Zhu, W. Y., Zhao, G. Z., Xu, L. H. and Li, W. J. (2009). Plantactinospora mayteni gen. nov., sp. nov., a member of the family Micromonosporaceae. International Journal of Systematic and Evolutionary Microbiology 59(10), 2527-2533.

Retchless, A. C. and Lawrence, J. G. (2012). Ecological adaptation in bacteria: Speciation driven by codon selection. Molecular Biology and Evolution 29(12), 3669-3683.

Rydén, A. C., Lindberg, M. and Philipson, L. (1973). Isolation and characterization of two proteaseproducing mutants from Staphylococcus aureus. Journal of Bacteriology 116(1), 25-32.

Saitou, N. and Nei, M. (1987). The neighbor-joining method: A new method for reconstructing 
phylogenetic trees. Molecular Biology and Evolution 4(4), 406-425.

Sazci, A., Erenler, K. and Radford, A. (1986). Detection of cellulolytic fungi by using Congo red as an indicator: A comparative study with the dinitrosalicyclic acid reagent method. Journal of Applied Bacteriology 61(6), 559-562.

Shirling, E. B. and Gottlieb, D. (1966). Methods for characterization of Streptomyces species. International Journal of Systematic and Evolutionary Microbiology 16(3), 313-340.

Stackebrandt, E. and Ebers, J. (2006). Taxonomic parameters revisited: Tarnished gold standards. Microbiology Today 33(4), 152-155.

Stackebrandt, E., Garrity, G. M., Trüper, H. G., Whitman, W. B., Grimont, P. A. D., Nesme, X., Frederiksen, W., Vauterin, L., Kämpfer, P., Rosselló-Mora, R., Ward, A. C., Maiden, M. C. J. and Swings, J. (2002). Report of the ad hoc committee for the re-evaluation of the species definition in bacteriology. International Journal of Systematic and Evolutionary Microbiology 52(3), 1043-1047.

Strobel, G. and Daisy, B. (2003). Bioprospecting for microbial endophytes and their natural products. Microbiology and Molecular Biology Reviews 67(4), 491-502.

Taechowisan, T., Peberdy, J. F. and Lumyong, S. (2003). Isolation of endophytic actinomycetes from selected plants and their antifungal activity. World Journal of Microbiology and Biotechnology 19(4), 381385.

Tamura, K., Nei, M. and Kumar, S. (2004). Prospects for inferring very large phylogenies by using the neighborjoining method. Proceedings of the National Academy of Sciences of the USA 101(30), 11030-11035.

Tamura, K., Stecher, G., Peterson, D., Filipski, A. and Kumar, S. (2013). MEGA6: Molecular Evolutionary Genetics Analysis version 6.0. Molecular Biology and Evolution 30(12), 2725-2729.

Thawai, C., Tanasupawat, S., Suwanborirux, K. and Kudo, T. (2010). Actinaurisporasiamensis gen. nov., sp. nov., a new member of the family Micromonosporaceae. International Journal of Systematic and Evolutionary Microbiology 60(7), 1660-1666.

Udwary, D. W., Zeigler, L., Asolkar, R. N., Singan, V., Lapidus, A., Fenical, W., Jensen, P. R. and Moore, B. S. (2007). Genome sequencing reveals complex secondary metabolome in the marine actinomycete Salinispora tropica. Proceedings of the National Academy of Sciences of the USA 104(25), 1037610381.

Velho-Pereira, S. and Kamat, N. M. (2011). Antimicrobial screening of actinobacteria using a modified cross-streak method. Indian Journal of Pharmaceutical Sciences 73(2), 223-228.

Wang, D., Yuan, J., Gu, S. and Shi, Q. (2013). Influence of fungal elicitors on biosynthesis of natamycin by
Streptomyces natalensis HW-2. Applied Microbiology and Biotechnology 97(12), 5527-5534.

Xing, H., Liu, C., Zhang, Y., Zhao, J., Li, C., Liu, H., Li, L., Wang, X. and Xiang, W. (2015). Plantactinospora veratri sp. nov., an actinomycete isolated from black false hellebore root (Veratrum nigrum L.). International Journal of Systematic and Evolutionary Microbiology 65, 1799-1804.

Xu, D. B., Ye. W. W., Han, Y., Deng, Z. X. and Hong, K. (2014). Natural products from mangrove actinomycetes. Marine Drugs 12(5), 2590-2613.

Zhu, W. Y., Zhao, L. X., Zhao, G. Z., Duan, X. W., Qin, S., Li, J., Xu, L. H. and Li, W. J. (2012). Plantactinospora endophytica sp. nov., an actinomycete isolated from Camptotheca acuminata Decne., reclassification of Actinaurispora siamensis as Plantactinospora siamensis comb. nov. and emended descriptions of the genus Plantactinospora and Plantactinospora mayteni. International Journal of Systematic and Evolutionary Microbiology 62(10), 2435-2442. 